H. D. Shin · B. L. Park - L. H. Kim • H. S. Cheong $\cdot$

J. H. Kim - Y. M. Cho - H. K. Lee - K. S. Park

\title{
Association of a polymorphism in the gene encoding phosphoenolpyruvate carboxykinase 1 with high-density lipoprotein and triglyceride levels
}

Received: 4 January 2005 / Accepted: 16 May 2005 / Published online: 31 August 2005

(C) Springer-Verlag 2005

\begin{abstract}
Aims/hypothesis: Phosphoenolpyruvate carboxykinase (PCK) is the key enzyme involved in the regulation of gluconeogenesis. The aim of this study was to identify genetic polymorphisms in potential candidate genes for type 2 diabetes by sequencing all exons in the $P C K$ genes (PCK1 and PCK2), and examining the association with type 2 diabetes and diabetic phenotypes in a Korean population (775 type 2 diabetic patients and 316 normal control subjects). Materials and methods: Twenty-two polymorphisms in $P C K 1$ and $P C K 2$ were identified in a Korean population $(n=24)$ by direct DNA sequencing. The TaqMan genotyping method was applied for genotyping] the remainder of the study population. Associations of $P C K$ polymorphisms with the risk of type 2 diabetes and diabetic phenotypes were analysed using logistic and multiple regressions, adjusting for age, sex and BMI. Results: Although no significant associations between the genetic polymorphisms in $P C K$ genes and the risk of type 2 diabetes were detected, in further haplotype analysis, one of the common haplotypes, $P C K 1$ ht 3 , revealed susceptibility to type 2 diabetes $(p=0.006)$. One $3^{\prime}$ untranslated region (UTR) single nucleotide polymorphism (SNP)
\end{abstract}

Electronic supplementary material Supplementary material is available for this article at http://dx.doi.org/10.1007/s00125005-1839-7 and accessible for authorised users.

H. D. Shin · B. L. Park · L. H. Kim · H. S. Cheong Department of Genetic Epidemiology, SNP Genetics, Seoul, Korea

J. H. Kim · Y. M. Cho · H. K. Lee · K. S. Park Genome Research Centre for Diabetes and Endocrine Disease, Clinical Research Institute, Seoul National University Hospital, Seoul, Korea

J. H. Kim · Y. M. Cho $\cdot$ K. S. Park $(\bowtie)$

Department of Internal Medicine,

Seoul National University College of Medicine,

28 Yongon-Dong, Chongro-Gu,

Seoul, 110-744, Korea

e-mail: kspark@snu.ac.kr

Tel.: +82-2-36768309

Fax: $+82-2-7601789$ also showed an association with HDL levels among nondiabetic control subjects: individuals homozygous for the major allele $(\mathrm{T} / \mathrm{T})$ had the lowest HDL level $(1.11 \pm$ $0.32 \mathrm{mmol} / \mathrm{l})$, heterozygotes $(\mathrm{T} / \mathrm{C})$ had an intermediate level $(1.27 \pm 0.37 \mathrm{mmol} / \mathrm{l})$, and those homozygous for the minor allele $(\mathrm{C} / \mathrm{C})$ had the highest level $(1.39 \pm 0.28 \mathrm{mmol} / \mathrm{l})$ $(p=0.000003)$. This $3^{\prime}$ UTR SNP was also associated with triglyceride levels, with a lower triglyceride level observed among individuals who were homozygous for the minor allele $(\mathrm{C} / \mathrm{C})$ than among those who were not. Conclusions/ interpretation: The strong genetic association of HDL and triglyceride levels with variation/haplotype information identified in this study would be useful for further genetic epidemiological studies of this important gene.

Keywords HDL - Phosphoenolpyruvate carboxykinase Polymorphism - Triglyceride - Type 2 diabetes mellitus

Abbreviations ESM: electronic supplementary material . HOMA $_{\text {IR }}$ : homeostasis model assessment for insulin resistance $\cdot$ ht: haplotype - LD: linkage disequilibrium PCK: phosphoenolpyruvate carboxykinase - SNP: single nucleotide polymorphism - UTR: untranslated region

\section{Introduction}

Phosphoenolpyruvate carboxykinases (PCKs) mainly function as enzymes that help to regulate gluconeogenesis, and have been implicated as candidate genes for type 2 diabetes mellitus. PCKs are found in the cytosol (encoded by PCK1; MIM 261680) and the mitochondria (encoded by PCK2; MIM 261650) [1,2]. The similar gene structures and the amino acid sequence homology of $68-70 \%$ between the cytosolic PCK1 and the mitochondrial PCK2 [3] suggest that they are derived from a common ancestor gene. The activity of PCK1 (on chromosome 20q13.31) is controlled by the rate of transcription of its gene, which is regulated by insulin, glucocorticoids, cAMP and diet, to adjust glucose production to meet physiological requirements [4], whereas PCK2 (on chromosome 14q11.2) seems to be constitutively 
active [4]. It has been proposed that PCK1 is best suited to gluconeogenesis from amino acids and that mitochondrial PCK2 best serves gluconeogenesis from lactate [4]. Recent evidence suggests that PCK may primarily function as an integrator of hepatic energy metabolism rather than as a determinant of gluconeogenesis $[1,5,6]$.

Previous studies had indicated that the $P C K 1$ region on chromosome $20 \mathrm{q}$ has a genetic linkage to type 2 diabetes. Using affected-sib-pair methods, significant results were obtained in the $20 \mathrm{q} 13$ region, in the vicinity of the PCK1 locus [7]. This was also reported as a candidate region for insulin resistance [8]. It is noteworthy that two other diabetes-susceptibility genes also map to chromosome $20 \mathrm{q}$, both of which are centromeric to the PCK1 locus, namely $M O D Y 1$, which causes a subtype of MODY, and the gene encoding the agouti signalling protein, non-agouti homologue (mouse) (ASIP), which is the human homologue of a murine gene responsible for an obesity-diabetes syndrome in mice $[9,10]$.

In an effort to identify genetic polymorphisms in potential candidate genes for type 2 diabetes, we sequenced all exons in PCK1 and PCK2, including the $-1.5 \mathrm{~kb}$ of the $5^{\prime}$ flanking region and $\pm 50 \mathrm{bp}$ exon-intron boundaries, and investigated associations with the risk of type 2 diabetes and diabetic phenotypes in a Korean population.

\section{Subjects and materials}

Subjects and measures A total of 775 unrelated patients with type 2 diabetes and 316 unrelated non-diabetic control subjects were recruited. Non-diabetic control subjects were recruited from an unselected population undergoing a routine health check-up at Seoul National University Hospital (Seoul, Korea). Inclusion criteria were as follows: 60 or more years of age, no past history of diagnosis of diabetes, no diabetes in first-degree relatives, fasting plasma glucose level $<6.1 \mathrm{mmol} / \mathrm{l}$ and $\mathrm{HbA}_{1} \mathrm{c}<5.8 \%$. The diabetic subjects were randomly recruited from patients attending the outpatient clinic of Seoul National University Hospital. Diabetes was diagnosed based on American Diabetes Association criteria [11]. Subjects who tested positive for anti-GAD antibodies were excluded. All subjects enrolled in this study were of Korean ethnicity. The study protocol was approved by the Institutional Review Board of the Clinical Research Institute at Seoul National University Hospital. Informed consent was obtained from all subjects before drawing blood samples. All study subjects were examined in the morning after an overnight fast. Height, weight, waist and hip circumferences and blood pressure were measured. Blood samples were drawn for biochemical measurements (fasting plasma glucose, postprandial 2-h glucose, fasting plasma insulin, $\mathrm{HbA}_{1} \mathrm{c}$, total cholesterol, triglyceride, and HDL cholesterol) and DNA extraction. The insulin resistance index HOMA IR $_{\text {(homeo- }}$ stasis model assessment) was calculated as fasting serum insulin $(\mathrm{mU} / \mathrm{l}) \times$ fasting plasma glucose $(\mathrm{mmol} / \mathrm{l}) / 22.5$ [12]. The clinical characteristics of the subjects are shown in Table 1.
Table 1 Clinical characteristics of type 2 diabetic patients and normal control subjects

\begin{tabular}{|c|c|c|}
\hline Parameter & $\begin{array}{l}\text { Type } 2 \text { diabetic } \\
\text { patients }\end{array}$ & $\begin{array}{l}\text { Normal } \\
\text { controls }\end{array}$ \\
\hline $\operatorname{Sex}(M / F)$ & $361 / 414$ & $146 / 170$ \\
\hline Age (years) & $58.9 \pm 10.5$ & $64.8 \pm 4.3$ \\
\hline $\operatorname{BMI}\left(\mathrm{kg} / \mathrm{m}^{2}\right)^{\mathrm{a}}$ & $24.4 \pm 2.9$ & $23.7 \pm 3.1$ \\
\hline WHR & $0.90 \pm 0.06$ & $0.89 \pm 0.06$ \\
\hline $\begin{array}{l}\text { Systolic blood pressure } \\
(\mathrm{mmHg})\end{array}$ & $134.5 \pm 20.0$ & $132.3 \pm 19.4$ \\
\hline $\begin{array}{l}\text { Diastolic blood pressure } \\
(\mathrm{mmHg})\end{array}$ & $80.8 \pm 11.9$ & $81.3 \pm 11.5$ \\
\hline $\mathrm{HOMA}_{\mathrm{IR}}^{\mathrm{a}}$ & $4.73 \pm 4.74$ & $1.85 \pm 0.98$ \\
\hline Total cholesterol (mmol/l) & $5.26 \pm 0.97$ & $5.07 \pm 0.89$ \\
\hline Triglycerides $(\mathrm{mmol} / \mathrm{l})^{\mathrm{a}}$ & $1.93 \pm 1.32$ & $1.57 \pm 0.81$ \\
\hline HDL cholesterol $(\mathrm{mmol} / \mathrm{l})^{\mathrm{b}}$ & $1.23 \pm 0.30$ & $1.17 \pm 0.35$ \\
\hline $\begin{array}{l}\text { Fasting blood glucose } \\
(\mathrm{mmol} / \mathrm{l})^{\mathrm{a}}\end{array}$ & $8.6 \pm 2.6$ & $5.2 \pm 0.7$ \\
\hline $\begin{array}{l}\text { Fasting serum insulin } \\
(\mathrm{pmol} / 1)^{\mathrm{a}}\end{array}$ & $86.4 \pm 81.3$ & $55.8 \pm 27.6$ \\
\hline $\mathrm{HbA}_{1} \mathrm{c}(\%)^{\mathrm{a}}$ & $8.08 \pm 1.63$ & $5.22 \pm 0.48$ \\
\hline
\end{tabular}

Data are means \pm SD

${ }_{p} p<0.001$

${ }^{\mathrm{b}} p<0.01$ for the difference between type 2 diabetes and normal control subjects

Sequencing analysis of the gene encoding human PCK We sequenced all exons, including exon-intron boundaries and the promoter region $(\sim 1.5 \mathrm{~kb})$, to discover single nucleotide polymorphisms (SNPs) in 24 Korean DNA samples using the ABI PRISM 3,700 DNA Analyzer (Applied Biosystems, Foster City, CA, USA). Twenty-two primer sets for the amplification and sequencing analysis were designed based on GenBank sequences (Ref. Seq. of PCK1 mRNA: NM 133263 and mRNA: NT 026437.11). Information regarding primers is available at Electronic supplementary material (ESM) Table 1. Sequence variants were verified by chromatograms.

Genotyping with fluorescence polarisation detection For genotyping of polymorphic sites, amplifying primers and probes were designed for TaqMan [13]. Primer Express (Applied Biosystems) was used to design both the PCR primers and the MGB TaqMan probes. One allelic probe was labelled with the FAM dye and the other with the fluorescent VIC dye. PCRs were run in the TaqMan Universal Master mix without UNG (Applied Biosystems), with PCR primer concentrations of $900 \mathrm{nmol} / \mathrm{l}$ and TaqMan MGB probe concentrations of $200 \mathrm{nmol} / \mathrm{l}$. Reactions were performed in a 384-well format in a total reaction volume of $5 \mu \mathrm{l}$ using $20 \mathrm{ng}$ of genomic DNA. The plates then were placed in a thermal cycler (PE 9700; Applied Biosystems) and heated at $50^{\circ} \mathrm{C}$ for $2 \mathrm{~min}$ and $95^{\circ} \mathrm{C}$ for $10 \mathrm{~min}$ followed by 40 cycles of $95^{\circ} \mathrm{C}$ for $15 \mathrm{~s}$ and $60^{\circ} \mathrm{C}$ for $1 \mathrm{~min}$. The TaqMan assay plates were transferred to a Prism 7900HT instrument (Applied Biosystems) in which the fluorescence intensity in each well of the plate was read. Fluorescence 
data files from each plate were analysed using automated software (SDS 2.1; Applied Biosystems). Information regarding the primers is shown in ESM Table 2.

Statistical analysis $\chi^{2}$ Tests were used to determine whether the individual variant was in Hardy-Weinberg equilibrium at each locus in the population. Haplotypes and their frequencies were inferred using the algorithm developed by Stephens et al. [14]. Logistic regression analyses were used for calculating $p$ values, controlling for age, sex and BMI as covariates. Multiple regressions, with adjustments for age, sex and BMI, were used for association analyses of metabolic phenotypes. Haplotype associations were analysed using the algorithm developed by Schaid et al. (Haplo.Score and Haplo.GLM) [15], controlling for age, sex and BMI as covariates. The insulin and triglyceride levels were logarithmically transformed to normalise skewed distribution. Only non-diabetic subjects were used for association analyses of metabolic phenotypes, as treatment of type 2 diabetes may have affected the phenotypic values in the diabetic patients.

\section{Results}

Fourteen polymorphisms were identified in $P C K 1$ : five in the $5^{\prime}$ flanking region, two in introns, five in exons, and two in $3^{\prime}$ untranslated regions (UTRs). Eight polymorphisms were identified in PCK2: two in the $5^{\prime}$ flanking region, one in an intron, and four in exons (see ESM Table 3). The locations and allele frequencies of identified polymorphic sites are shown in Fig. 1a and b. By pair-wise linkage analysis with 24 Korean DNA samples, which were used for direct sequencing, we found that two sets of SNPs in $P C K 1$ were in absolute linkage disequilibrium (LD) $\left(\left|D^{\prime}\right|=1\right.$ and $r^{2}=1$ ) (see Fig. 1a).
Among the identified polymorphisms, six SNPs in PCK1 $(+69 \mathrm{~A}>\mathrm{G},+1428 \mathrm{C}>\mathrm{G},+1573 \mathrm{G}>\mathrm{C},+3404 \mathrm{~T}>\mathrm{C},+4513 \mathrm{~T}>\mathrm{G}$ and $+4824 \mathrm{~T}>\mathrm{C})$ and four SNPs in PCK2 $(-403 \mathrm{C}>\mathrm{T}$, $+3894 \mathrm{~T}>\mathrm{C},+5804 \mathrm{~A}>\mathrm{G}$ and $+8881 \mathrm{C}>\mathrm{G})$ were selected for larger-scale genotyping based on location (SNPs in exons were preferred), LD (only one SNP if there are absolute LDs), frequency $(>0.05)$ and haplotype tagging status. A $>97 \%$ genotyping success rate was obtained (on average) by the TaqMan method. Genotyping quality control was performed by duplicate checking of $10 \%$ of the samples. No mismatches were detected among duplicates. Six common haplotypes in PCK1 and four common haplotypes in $P C K 2$ were constructed in a Korean population (Fig. 1b,d). The minor allele frequencies of genotyped polymorphisms were $0.391(P C K 1+69 \mathrm{~A}>\mathrm{G}$ [Leu23Leu]), $0.27(P C K 1+$ $1428 \mathrm{C}>\mathrm{G}$ [Leu184Val]), $0.281(P C K 1+1573 \mathrm{G}>\mathrm{C}), 0.356$ $(P C K 1+3404 \mathrm{C}>\mathrm{T}), 0.216(P C K 1+4513 \mathrm{~T}>\mathrm{G}), 0.222(P C K 1+$ 4824T $>\mathrm{C}), 0.487(P C K 2-403 \mathrm{C}>\mathrm{T}), 0.202(P C K 2+3894 \mathrm{~T}$ $>\mathrm{C}$ [Pro124Pro]), 0.212 (PCK2+5804A $>$ G [Lys410Lys]) and $0.364(P C K 2+8881 \mathrm{C}>\mathrm{G})$ in the Korean population $(n=1091$, see ESM Table 3$)$.

The genotype distributions of all loci were in HardyWeinberg equilibrium ( $p>0.05$, ESM Table 3). Among common haplotypes identified among the Korean population, only those with frequencies $>0.05$ were used for further analysis (Fig. 1b,d). Haplotypes that were mostly $(>90 \%)$ tagged by single SNPs were not used for further analysis (ht2 in $P C K 1$, ht3 in $P C K 2$ ).

Associations of $P C K$ polymorphisms with the risk of type 2 diabetes and diabetic phenotypes were analysed using logistic and multiple regressions, adjusting for age, sex and BMI (775 type 2 diabetic patients and 316 normal control subjects). The clinical characteristics of subjects are shown in Table 1. Our study was designed to detect common variants that might be involved in the risk of type 2 diabetes and relative phenotypes.
Table 2 Logistic analysis of $P C K$ polymorphisms with the risk of type 2 diabetes among patients and normal subjects
Minor allele frequencies of each site and $p$ values for logistic analyses of the co-dominant model, controlling for age, sex and BMI as covariates, are shown

${ }^{\mathrm{a}} p$ values of haplotype associations were calculated by the algorithm developed by Schaid et al. (Haplo.Score) [15], controlling for age, sex and BMI as covariates

\begin{tabular}{|c|c|c|c|c|c|c|}
\hline Gene & Locus & Location & $\begin{array}{l}\text { Amino acid } \\
\text { change }\end{array}$ & $\begin{array}{l}\text { Type } 2 \text { diabetic } \\
\text { patients }(n=775)\end{array}$ & $\begin{array}{l}\text { Controls } \\
(n=316)\end{array}$ & $p^{\mathrm{a}}$ \\
\hline \multirow[t]{11}{*}{ PCK1 } & $+69 A>G$ & Exon 2 & Leu23Leu & 0.39 & 0.38 & 0.79 \\
\hline & $+1428 \mathrm{C}>\mathrm{G}$ & Exon 4 & Leu184Val & 0.27 & 0.28 & 0.37 \\
\hline & $+1573 \mathrm{G}>\mathrm{C}$ & Intron 4 & - & 0.29 & 0.26 & 0.21 \\
\hline & $+3404 \mathrm{~T}>\mathrm{C}$ & Intron 8 & - & 0.35 & 0.39 & 0.08 \\
\hline & $+4513 \mathrm{~T}>\mathrm{G}$ & 3' UTR & - & 0.21 & 0.23 & 0.14 \\
\hline & $+4824 \mathrm{~T}>\mathrm{C}$ & 3' UTR & - & 0.22 & 0.23 & 0.87 \\
\hline & ht1 & - & - & 0.20 & 0.18 & 0.29 \\
\hline & ht3 & - & - & 0.15 & 0.11 & 0.006 \\
\hline & ht4 & - & - & 0.09 & 0.08 & 0.43 \\
\hline & ht5 & - & - & 0.08 & 0.09 & 0.46 \\
\hline & ht6 & - & - & 0.06 & 0.07 & 1.00 \\
\hline \multirow[t]{7}{*}{$P C K 2$} & $-403 \mathrm{C}>\mathrm{T}$ & $5^{\prime}$ & - & 0.49 & 0.48 & 0.82 \\
\hline & $+3894 \mathrm{~T}>\mathrm{C}$ & Exon 3 & Pro124Pro & 0.21 & 0.19 & 0.21 \\
\hline & $+5804 \mathrm{~A}>\mathrm{G}$ & Exon 7 & Lys410Lys & 0.22 & 0.20 & 0.22 \\
\hline & $+8881 \mathrm{C}>\mathrm{G}$ & Intron 9 & - & 0.36 & 0.36 & 0.94 \\
\hline & ht1 & - & - & 0.32 & 0.32 & 0.98 \\
\hline & ht 2 & - & - & 0.25 & 0.26 & 0.29 \\
\hline & ht4 & - & - & 0.19 & 0.19 & 0.71 \\
\hline
\end{tabular}




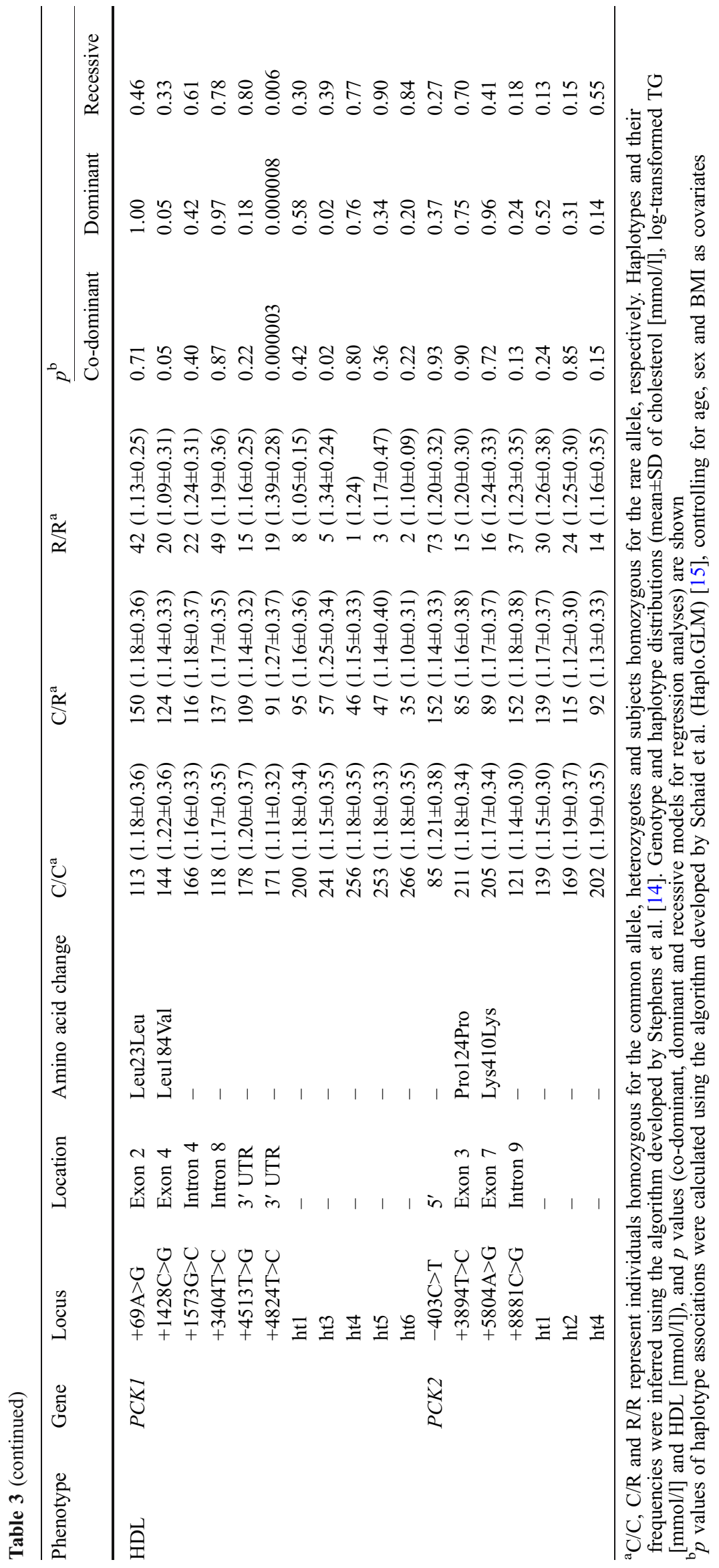


$\mathbf{a}$

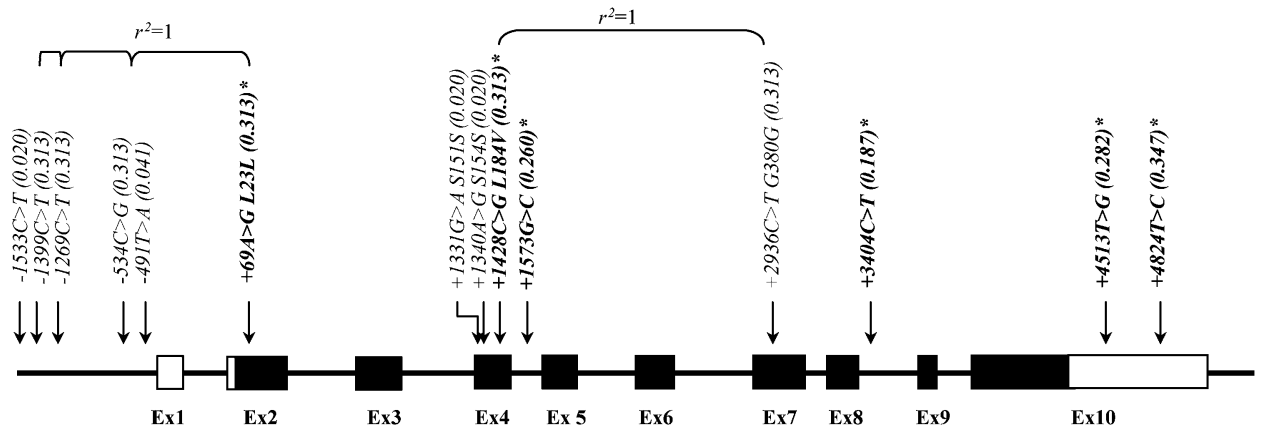

c
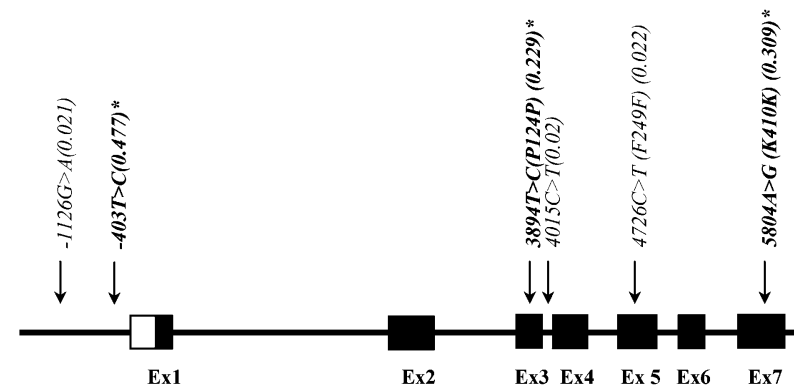

Fig. 1 Gene maps and haplotypes of $P C K$ genes (PCK1 and PCK2). Coding exons are marked by black blocks, and 5' and 3' UTRs by white blocks. The first base of the translational start site is denoted as nucleotide +1 . Asterisks indicate polymorphisms genotyped in a larger population $(n=1,087)$. The frequencies of polymorphisms not subjected to larger scale genotyping were based on sequence data $(n=24)$. a Polymorphisms identified in PCK1 on chromosome 20q13.31 (Ref. Genome Seq. NT 011362.9). b Haplotypes of PCK1. Haplotypes with frequencies $>0 . \overline{0} 5$ are shown. Others* contain rare

Only non-diabetic subjects were used for association analyses of metabolic phenotypes, including cholesterol, log-transformed triglyceride, HDL, log-transformed insulin and BMI, because treatment for type 2 diabetes may affect these values.

Although no significant associations between the genetic polymorphisms in $P C K$ genes and the risk of type 2 diabetes were detected, in further haplotype analysis one of the common haplotypes, $P C K 1 \mathrm{ht} 3$, revealed susceptibility to type 2 diabetes $(p=0.006$, Table 2$)$.

No reliable associations were detected with fasting blood

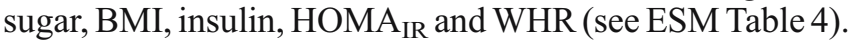
However, several SNPs and haplotypes have significant correlations with various metabolic traits (cholesterol: $P C K 1+3404 \mathrm{~T}>\mathrm{C}$ and $P C K 1 \mathrm{ht} 1$; log-transformed triglyceride: $P C K 1+4824 \mathrm{~T}>\mathrm{C}$ and $P C K 1$ ht1; HDL: $+1428 C>G$, $+4824 T>C$ and PCK1 ht3) (Table 3). Among them, one 3' UTR SNP, $+4824 T>C$, showed a gene-dose-dependent association with HDL levels among non-diabetic control subjects: individuals who were homozygous for the major allele $(\mathrm{T} / \mathrm{T})$ had the lowest HDL level $(1.11 \pm 0.32 \mathrm{mmol} / \mathrm{l})$, heterozygotes $(\mathrm{T} / \mathrm{C})$ had an intermediate level $(1.27 \pm$ $0.37 \mathrm{mmol} / \mathrm{l}$ ), and individuals homozygous for the minor allele $(\mathrm{C} / \mathrm{C})$ had the highest level $(1.39 \pm 0.28 \mathrm{mmol} / \mathrm{l})$ TCGG, CCGC, CCAG and CTGC

\section{Discussion}

b

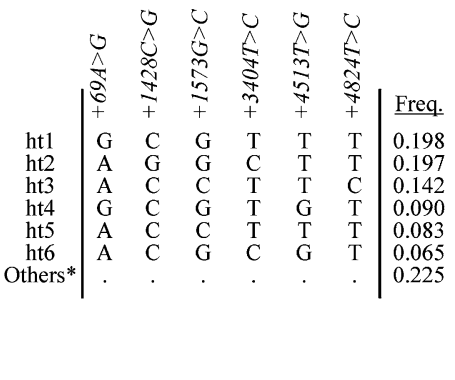

d

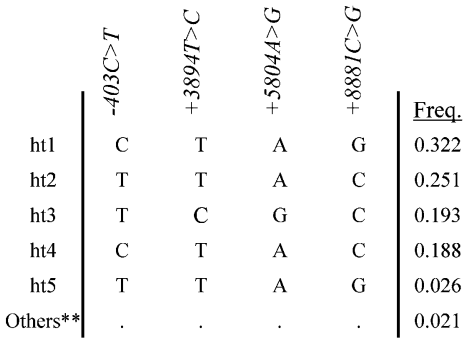

haplotypes: GCGTTC, ACGCTT, AGCTTT, ACGCTC, GG GTGT, GCCTTT, AGGTTT, AGGCGT, GGGTTT, GCGTGC, AC GCGC, GCGCGT, GCGCTT, ACCTGT, GCCTTC, ACGTTT, GCGCGC, GGGCTT, ACCTGC, GGGCGT, GCCTGT, AGCCTT, ACCCTC, ACCCTT, GCGCTC, AGGCGC and ACG TTC. $\mathbf{c}$ Poly morphisms identified in PCK2 on chromosome 14q11.2 (Ref. Genome Seq. NT 026437.11). d Haplotypes of PCK2. Haplotypes with frequencies $>0.02$ are shown. Others** contain rare haplotypes: TTGG,

( $p=0.000003$, Table 3 ). In addition, this $3^{\prime}$ UTR SNP was also associated with triglyceride levels; a lower triglyceride level was found among individuals who were homozygous for the minor allele $(\mathrm{C} / \mathrm{C})$ than those who were not.

In additional analysis, $3^{\prime}$ UTR SNP and PCK1 ht3 also showed significant association ( $p=0.002$ and 0.0002 , respectively) with BMI among diabetic subjects, but these significant associations were unreliable because the treatment for type 2 diabetes might have affected the phenotypic values in diabetics (see ESM Table 5).

In a previous report [16], one promoter SNP $(-232 \mathrm{C}>\mathrm{G}$; $-534 \mathrm{C}>\mathrm{G}$ in this study), which is in absolute LD $\left(\left|\mathrm{D}^{\prime}\right|=1\right.$ and $\left.r^{2}=1\right)$ with three nearby SNPs $(-1,399 \mathrm{C}>\mathrm{T},-1,269$ $\mathrm{C}>\mathrm{T},-534 \mathrm{C}>\mathrm{G},+69 \mathrm{~A}>\mathrm{G}$, Fig. 1a), was reported to be associated with the risk of type 2 diabetes in both Oji-Cree and Caucasian populations. However, no significant association was revealed in the Korean population. PCK1 ht3 only showed significant association with the risk of type 2 diabetes. Although it is hard to decipher the discrepancies between the previous study and the present study, a dif- 
ferent genetic background and environmental factors or their interaction among different ethnic groups could be a plausible explanation.

In the present study, the significance of the association ( $p=0.000003$ in the co-dominant model) between HDL and this $3^{\prime}$ UTR SNP $(P C K 1+4824 \mathrm{~T}>\mathrm{C})$ was retained even after the strictest correction for multiple tests (170 tests: 17 comparisons in case-control, 17 comparisons in five different diabetic phenotypes [cholesterol, triglyceride, HDL, insulin and BMI] with three alternative analysing models [co-dominant, dominant and recessive models]).

Although the mechanisms involved in the different HDL and triglyceride levels associated with the alternative genotypes in the 3' UTR are not currently understood, there are several possible explanations. The crucial role of the noncoding portion of genomes is now widely acknowledged. In particular, mRNA UTRs are involved in many post-transcriptional regulatory pathways that control mRNA localisation, stability and translation efficiency. Initiation of protein synthesis could be influenced by sequence elements in both 5' and 3' UTRs. The post-transcriptional events play an important yet incompletely understood role in regulatory gene expression and cellular behaviour; many of the identified cis-acting elements for translational regulation occur within the 3' UTR [17].

Recent data suggest that PCK1 is involved in glyceroneogenesis as well as gluconeogenesis [1,2]. Glyceroneogenesis in both liver and adipose tissue is the de novo synthesis of glycerol 3-phosphate from gluconeogenic precursors. Each glycerol 3-phosphate is used to esterify fatty acyl-CoA to form triglyceride. It has been shown that mice lacking hepatic PCK1 develop fatty livers and have elevated plasma fatty acids and triglyceride levels following a fast $[1,5,6]$. It has also been reported that removal of PCK1 results in an increase in the mitochondrial redox state and dramatic inhibition of the TCA cycle, which results in reduced oxidation of fats via beta oxidation, reduced production of ketones and subsequent hepatic steatosis [18]. These results suggest that mutations in PCK1 may affect glyceroneogenesis and/or cataplerosis, which would affect the storage and release of fatty acids. Further biological and/or functional evidence would be needed to clarify the mechanism(s) involved in different blood HDL and triglyceride levels mediated by alternative PCK1 polymorphisms.

In summary, 22 polymorphisms in $P C K 1$ and $P C K 2$ were identified in a Korean population $(n=24)$ by direct DNA sequencing. Associations of $P C K$ polymorphisms with the risk of type 2 diabetes and diabetic phenotypes were analysed using logistic and multiple regression analyses, with adjustment for age, sex and BMI. Although no significant associations between the genetic polymorphisms in $P C K$ genes and the risk of type 2 diabetes were detected, it was revealed that $P C K 1 \mathrm{ht} 3$ is significantly associated with the risk of type 2 diabetes $(p=0.006)$. One $3^{\prime}$ UTR SNP, +4824T $>$ C, was strongly associated with HDL and triglyceride levels among non-diabetic control subjects $(p=0.000003)$.
Although the statistical power to detect significant association of this study (775 type 2 diabetic patients and 316 normal control subjects) might be low for rare variants, our study was designed to detect common variants that might be involved in the risk of type 2 diabetes. In addition, the differences in quantitative traits (which are dependent on sample sizes [genotype distributions], means of traits and SDs among populations) among 316 normal controls might not be detected, especially for rare allele (e.g. unequal sample sizes for populations).

Although our results showed several significant associations of polymorphisms with various metabolic traits (cholesterol, log-transformed triglyceride and HDL), replication of our finding in an independent dataset and/or functional validation of polymorphisms should be performed in the future. The strong association of HDL and triglyceride levels with the $P C K 1$ polymorphism and the variation/haplotype information identified in this study would be useful for genetic epidemiological studies of other metabolic diseases.

Acknowledgements This work was supported by a grant from the National Research Laboratory, a part of the National Research and Development Program of the Ministry of Science and Technology of Korea; Contract grant number M1-0302-00-0073.

\section{References}

1. Beale EG, Hammer RE, Antoine B, Forest C (2004) Disregulated glyceroneogenesis: PCK1 as a candidate diabetes and obesity gene. Trends Endocrinol Metab 15:129-135

2. Nordlie RC, Lardy HA (1963) Mammalian liver phosphoneolpyruvate carboxykinase activities. J Biol Chem 238:2259-2263

3. Modaressi S, Christ B, Bratke J, Zahn S, Heise T, Jungermann $\mathrm{K}$ (1996) Molecular cloning, sequencing and expression of the cDNA of the mitochondrial form of phosphoenolpyruvate carboxykinase from human liver. Biochem J 315:807-814

4. Watford M, Hod Y, Chiao YB, Utter MF, Hanson RW (1981) The unique role of the kidney in gluconeogenesis in the chicken. The significance of a cytosolic form of phosphoenolpyruvate carboxykinase. J Biol Chem 256:10023-10027

5. Beale EG, Forest C, Hammer RE (2003) Regulation of cytosolic phosphoenolpyruvate carboxykinase gene expression in adipocytes. Biochimie 85:1207-1211

6. She P, Shiota M, Shelton KD, Chalkley R, Postic C, Magnuson MA (2000) Phosphoenolpyruvate carboxykinase is necessary for the integration of hepatic energy metabolism. Mol Cell Biol 20:6508-6517

7. Zouali H, Hani EH, Philippi A et al (1997) A susceptibility locus for early-onset non-insulin dependent (type 2) diabetes mellitus maps to chromosome $20 \mathrm{q}$, proximal to the phosphoenolpyruvate carboxykinase gene. Hum Mol Genet 6:14011408

8. Hani el H, Zouali H, Philippi A et al (1996) Indication for genetic linkage of the phosphoenolpyruvate carboxykinase (PCK1) gene region on chromosome $20 \mathrm{q}$ to non-insulin-dependent diabetes mellitus. Diabetes Metab 22:451-454

9. Bell GI, Xiang KS, Newman MV et al (1991) Gene for noninsulin-dependent diabetes mellitus (maturity-onset diabetes of the young subtype) is linked to DNA polymorphism on human chromosome 20q. Proc Natl Acad Sci U S A 88:1484-1488

10. Wilson BD, Ollmann MM, Kang L, Stoffel M, Bell GI, Barsh GS (1995) Structure and function of ASP, the human homolog of the mouse agouti gene. Hum Mol Genet 4:223-230 
11. Committee E (1997) Report of the expert committee on the diagnosis and classification of diabetes mellitus. Diabetes Care 20:1183-1197

12. Matthews DR, Hosker JP, Rudenski AS, Naylor BA, Treacher DF, Turner RC (1985) Homeostasis model assessment: insulin resistance and beta-cell function from fasting plasma glucose and insulin concentrations in man. Diabetologia 28:412-419

13. Livak KJ (1999) Allelic discrimination using fluorogenic probes and the 5' nuclease assay. Genet Anal 14:143-149

14. Stephens M, Smith NJ, Donnelly P (2001) A new statistical method for haplotype reconstruction from population data. Am J Hum Genet 68:978-989

15. Schaid DJ, Rowland CM, Tines DE, Jacobson RM, Poland GA (2002) Score tests for association between traits and haplotypes when linkage phase is ambiguous. Am J Hum Genet 70:425434
16. Cao H, van der Veer E, Ban MR et al (2004) Promoter polymorphism in PCK1 (phosphoenolpyruvate carboxykinase gene) associated with type 2 diabetes mellitus. J Clin Endocrinol Metab 89:898-903

17. Conklin D, Jonassen I, Aasland R, Taylor WR (2002) Association of nucleotide patterns with gene function classes: application to human $3^{\prime}$ untranslated sequences. Bioinformatics 18:182-189

18. Burgess SC, Hausler N, Merritt M et al (2004) Impaired tricarboxylic acid cycle activity in mouse livers lacking cytosolic phosphoenolpyruvate carboxykinase. J Biol Chem 279: 4894148949 